Research Article

\title{
A Constitutive Model of Sandy Gravel Soil under Large-Sized Loading/Unloading Triaxial Tests
}

\author{
Pengfei Zhang, ${ }^{1}$ Han Liu, ${ }^{1}$ Zhentu Feng, ${ }^{2}$ Chaofeng Jia, ${ }^{2}$ and Rui Zhou $\mathbb{D}^{3}$ \\ ${ }^{1}$ Hebei Research Institute of Construction and Geotechnical Investigation Co. Ltd., Shijiazhuang 050031, China \\ ${ }^{2}$ Luoyang Rail Transit Group Co Ltd., Luoyang 471000, Henan, China \\ ${ }^{3}$ School of Civil Engineering, Beijing Jiaotong University, Beijing 100044, China
}

Correspondence should be addressed to Rui Zhou; 18121179@bjtu.edu.cn

Received 23 April 2021; Accepted 2 June 2021; Published 14 June 2021

Academic Editor: Faming Huang

Copyright ( $\odot 2021$ Pengfei Zhang et al. This is an open access article distributed under the Creative Commons Attribution License, which permits unrestricted use, distribution, and reproduction in any medium, provided the original work is properly cited.

Based on large-scale triaxial tests of sandy gravel materials, the strength and deformation characteristics under loading/unloading conditions are analyzed. At the same time, the applicability of the hyperbolic constitutive model to sandy gravel is studied using experimental data. The results indicate that sandy gravel under low confining pressures $(0.2$ and $0.4 \mathrm{MPa})$ shows a weak softening trend; the higher the confining pressure, the more obvious the hardening tendency ( 0.6 and $0.8 \mathrm{MPa})$ and the greater the peak strength. During unloading tests, strain softening occurs, and the peak strength increases with increasing confining pressure. During loading tests, dilatancy appears when the confining pressure is low $(0.2 \mathrm{MPa})$. With increasing confining pressure $(0.4,0.6$, and $0.8 \mathrm{MPa}$ ), the dilatancy trend gradually weakens, and the cumulative volume tric strain increases, which reflects the relevance of the stress paths. Through research, it is found that the hyperbolic constitutive model has good applicability to sandy gravel soils, and the corresponding model parameters are obtained.

\section{Introduction}

With the rapid development of rail transit, shield tunnel construction has encountered many severe challenges in sandy gravel strata in China. For example, the first phase of the Luoyang Urban Rail Transit Line 2 project under construction uses the shield method to cross the sandy gravel stratum, which is particularly important for the ground settlement, seepage damage, and the stability of the excavation surface [1-3]. In addition to a large number of field tests, the mechanical characteristics and description of the stress-strain relationship of coarse-grained soil are hot topics $[4,5]$, which can provide necessary conditions for numerical calculations in practical engineering.

The mechanical properties of soils are determined by many factors, including externally applied stress, soil type, microstructure damage [6], density, matrix suction caused by surface tension passing through the air in unsaturated environments [7], and temperature [8-10]. To date, many constitutive models of saturated/unsaturated soil have been proposed, but there are still many controversies regarding some basic problems $[9,11]$, such as the selection of state variables of stress and strain and the theoretical framework of hydraulic coupling processes [12, 13]. Alonso et al. [14] established a constitutive model of unsaturated soil materials by utilizing the double-stress variables of net stress and matrix suction. Many scholars $[15,16]$ have discussed the hydraulic coupling characteristics of saturated/unsaturated soil and even some basic thermo-hydromechanical coupling characteristics $[17,18]$. These theoretical studies considered the influence of the volume water content on mechanical properties, such as irreversible compression during drying and changes in the water content during loading/unloading. Based on the principle of thermodynamics, some researchers [19-21] established the hydraulic coupling effects of threephase unsaturated soil by analyzing the thermodynamic potential of the solid-liquid-gas phase and dissipated energy. Recently, Bai et al. [22] proposed a thermo-hydromechanical constitutive model for geomaterials in view of the concept of particle rearrangement during the thermodynamic process 
of porous granular materials, which is contributed to understand the mechanical properties of the particle movement of sandy gravel soils from the microscopic point of view.

For subway tunnel projects in sandy gravel strata [23-25], when discussing settlement control and deformation characteristics, the constitutive relationship of sandy gravel is rarely mentioned, and the commonly used Mohr-Coulomb relationship is still utilized [26]. The actual sandy gravel is a kind of coarse-grained soil; however, it is not reasonable to use the Mohr-Coulomb relationship. Therefore, it is particularly important to study the deformation characteristics of shield tunneling in sandy gravel formations and to determine the appropriate constitutive model and parameters [27, 28]. It has important engineering significance in stratum settlement control and station foundation pit excavation [29].

In this paper, a large-sized laboratory triaxial shear test is carried out on sandy gravel soil taken from the Luoyang subway site, and then triaxial shear tests on sandy gravel under different confining pressures are carried out to determine the appropriate sandy gravel constitutive model as well as the model parameters accordingly. This work can help with engineering design and practice. The established constitutive model can well reflect the loading process and unloading process of sandy gravel soil, which is also used for the numerical calculation during the unloading process in the shield tunnel excavation process.

\section{Experiments of Large Sandy Gravel Soil under a Complex Stress Path}

2.1. Test Schemes. This paper selects sandy gravel soil samples from the first phase of the project of Luoyang Urban Rail Transit Line 2 to conduct a large-scale triaxial test. The purpose is to investigate two typical stress state change processes (namely, loading and unloading stress paths) and then determine the stress-strain relationship characteristics and volumetric strain-axial strain characteristics, as well as the seepage effect $[30,31]$ and damage mechanism of the soil layer $[24,32,33]$.

Actually, the stress and deformation state changes of the surrounding stratum are very complicated during the shield tunnel excavation process $[34,35]$, even related to the effect of environmental temperature [36,37] and the thermalmechanical behavior of tunnel lining segments $[38,39]$. For simplicity, this test simulates two extreme stress path change processes, namely, active failure and passive failure of the excavation surface. The specific test scheme is shown in Table 1, including 2 groups of tests. Among them, the sample size is $30 \mathrm{~cm}$ in diameter and $70 \mathrm{~cm}$ in height, and the test confining pressure is determined by the actual stress state at the site to be $200,400,600$, and $800 \mathrm{kPa}$. The loading/ unloading tests were accomplished by the stress-controlled method, and the shear rate was $0.2 \mathrm{kPa} / \mathrm{s}$. This test primarily studies the strength and deformation characteristics of sandy gravel under triaxial compression and unloading conditions.
2.2. Preparation of Soil Samples. The soil layer in the project area is composed of silty clay, silt soil, a sand layer, and a gravel soil layer, which is a multilayer structure. According to the actual situation of the project, samples were taken at a depth of $10 \mathrm{~m}$, and the dry density was controlled to be $2.27 \mathrm{~g} / \mathrm{cm}^{3}$.

Through particle analysis, the maximum particle size of sandy gravel tested was $80 \mathrm{~mm}$, and its characteristic particle size is shown in Table 2. The inhomogeneity coefficient of the soil is greater than 10 , and the curvature coefficient is between 1 and 5. It belongs to coarse-grained soil with good gradation.

The test equipment was an SJ70 large-scale high-pressure triaxial shear tester. The test specimen has a diameter of $300 \mathrm{~mm}$ and a height of $700 \mathrm{~mm}$. According to the sampling and sieving situation, the gravels that exceed the particle size limit of $60 \mathrm{~mm}$ account for only approximately 5\%, so a particle size of $40-60 \mathrm{~mm}$ was used instead. The sample was prepared by splitting the soil into 5 layers. The sample preparation method uses a vibrator to vibrate. The static pressure of the vibrator bottom plate is $14 \mathrm{kPa}$, and the vibration frequency is $40 \mathrm{~Hz}$. The vibration time is determined according to the dry density of the sample.

According to the actual engineering conditions and the high water permeability of sandy gravel, this test adopts the consolidated drained shear (i.e., CD) test. The sample saturation method adopts the suction saturation method.

\section{Test Results and Analysis}

3.1. Stress-Strain-Strength Characteristics. From the stressstrain relationship curves of sandy gravel in Figures 1 and 2, under the condition of the same shear rate, sandy gravel is loaded under low confining pressure $(0.2$ and $0.4 \mathrm{MPa})$, showing a weak softening trend. The higher the confining pressure, the more obvious the hardening tendency ( 0.6 and $0.8 \mathrm{MPa}$ ) and the greater the peak strength. For the unloading test, there is a more obvious softening phenomenon, and as the confining pressure increases, the peak value becomes more obvious. The deviator stress-strain curves of the two groups of sandy gravels show a strong nonlinear relationship when the stress and strain reach a certain value.

3.2. Volume Deformation Characteristics. Figures 3 and 4 give the $\varepsilon_{v}-\varepsilon_{a}$ relationship of sandy gravel when loading and unloading under different confining pressures. From Figure 3, under conditions of low confining pressure $(0.2 \mathrm{MPa})$, sandy gravels exhibit shear shrinkage first and then dilatancy. As the confining pressure increases $(0.4,0.6$, and $0.8 \mathrm{MPa}$ ), the dilatancy trend gradually weakens, and the cumulative body strain increases. Under unloading conditions (Figure 4), the main manifestation is dilatancy, and with increasing confining pressure, the dilatancy phenomenon becomes more obvious, which fully reflects the relevance of the stress path. 
TABLE 1: Test schemes for large-size specimens.

\begin{tabular}{lcccc}
\hline Test number & Load path & Loading/unloading & Confining pressure (kPa) & Number of soil samples \\
\hline 1 & $\begin{array}{l}\sigma_{3}=\text { constant, } \\
\sigma_{1}=\text { increases }\end{array}$ & Loading & $200,400,600,800$ & 4 \\
\hline 2 & $\begin{array}{l}\sigma_{1}=\text { constant, } \\
\sigma_{3}=\text { decreases }\end{array}$ & Unloading & $200,400,600,800$ & 4 \\
\hline
\end{tabular}

TABLE 2: Particle gradation of sandy gravel samples.

\begin{tabular}{lccccccccc}
\hline Particle size $(\mathrm{mm})$ & 80 & 60 & 20 & 10 & 5 & 1 & 0.5 & 0.25 & 0.1 \\
\hline Cumulative percentage (\%) & 100 & 96.9 & 58.9 & 42.9 & 34.5 & 30.5 & 29.1 & 16.85 & 0 \\
\hline
\end{tabular}

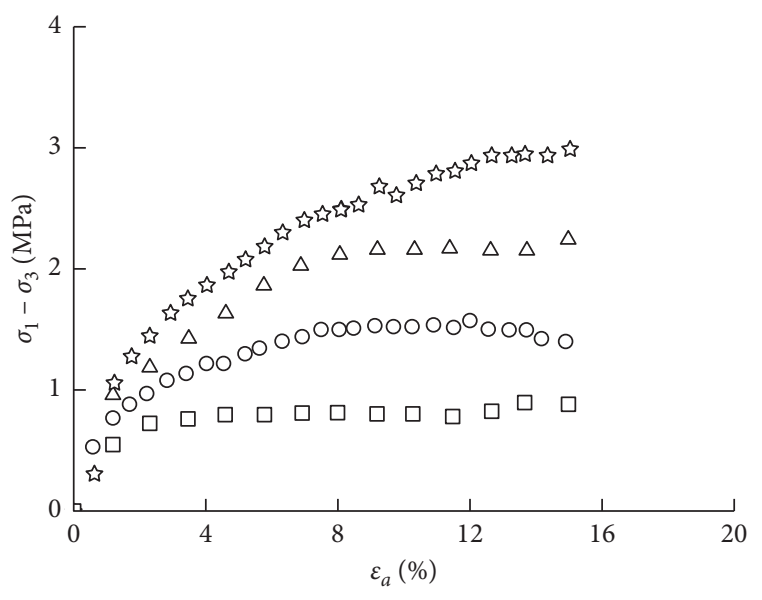
$\sigma_{3}(\mathrm{MPa})$
$\square 0.2$
$\triangle 0.6$
○ 0.4
is 0.8

Figure 1: Axial stress-strain curve of sandy gravel soil under loading conditions.

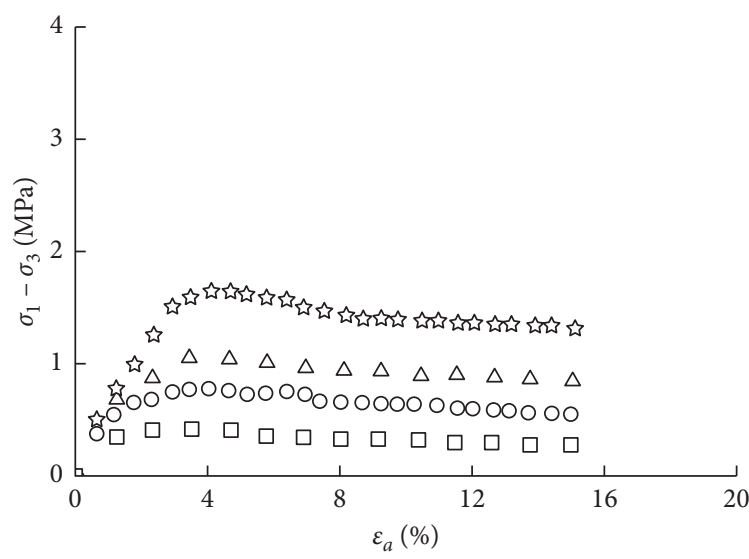

$$
\begin{array}{ll}
\sigma_{3}(\mathrm{MPa}) & \\
\square 0.2 & \triangle 0.6 \\
\circ 0.4 & \text { 方 } 0.8
\end{array}
$$

FIGURE 2: Axial stress-strain curve of sandy gravel soil under unloading conditions.

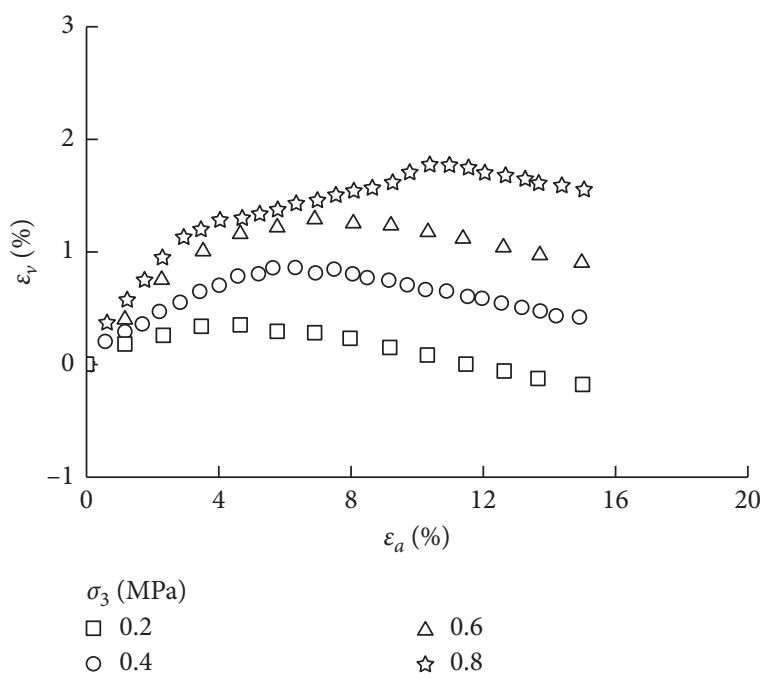

FIgURE 3: Curve of volumetric strain-axial strain under loading conditions.

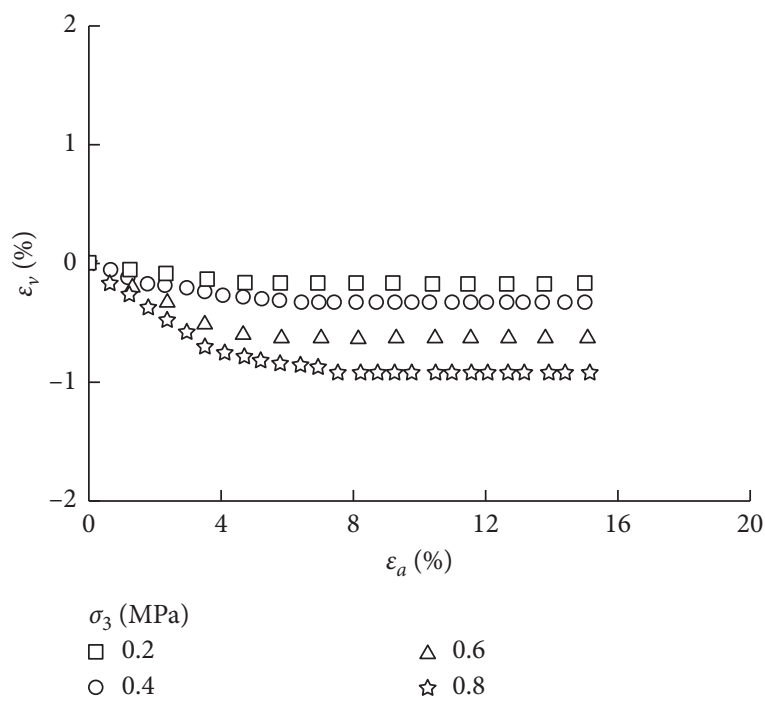

FIgURE 4: Curve of volumetric strain-axial strain under unloading conditions. 


\section{Constitutive Model of Sandy Gravel Considering the Loading/ Unloading Process}

Kondner [40] thought that the hyperbola can be used to fit the general triaxial test $\left(\sigma_{1}-\sigma_{3}\right)-\varepsilon_{1}$ curve, namely,

$$
\left(\sigma_{1}-\sigma_{3}\right)=\frac{\varepsilon_{a}}{a+b \varepsilon_{a}}
$$

where $a$ and $b$ are test constants.

For the conventional triaxial shear test, $\varepsilon_{a}=\varepsilon_{1}$. Later, Duncan and Chang [41] proposed a widely used nonlinear elastic model, namely, the Duncan-Chang model, which was developed widely [42].

4.1. Conventional Triaxial Loading Test. Under conventional triaxial loading conditions, (1) can be written as

$$
\frac{\varepsilon_{1}}{\left(\sigma_{1}-\sigma_{3}\right)}=a+b \varepsilon_{1}
$$

where $a$ is the intercept of the line and $b$ is the slope of the line.

Obviously, there is an approximately linear relationship between $\varepsilon_{1} /\left(\sigma_{1}-\sigma_{3}\right)$ and $\varepsilon_{1}$. In the conventional triaxial shear test, the tangent elastic modulus can be expressed as

$$
\begin{aligned}
E_{t} & =\frac{d\left(\sigma_{1}-\sigma_{3}\right)}{d \varepsilon_{1}}, \\
& =\frac{a}{\left(a+b \varepsilon_{1}\right)} .
\end{aligned}
$$

When $\varepsilon_{1}=0$ and $E_{t}=E_{i}$, the combination of (3) leads to

$$
E_{i}=\frac{1}{a} \text {. }
$$

When $\varepsilon_{1} \longrightarrow \infty$, from (1), we can get

$$
\left(\sigma_{1}-\sigma_{3}\right)_{\mathrm{ult}}=\frac{1}{b}
$$

In (4) and (5), $a$ represents the reciprocal of the initial elastic modulus $E_{i}$, and $b$ represents the reciprocal of the ultimate deviator stress $\left(\sigma_{1}-\sigma_{3}\right)_{\mathrm{ult}}$ corresponding to the asymptote of the hyperbola.

In the conventional triaxial test, the shear strength $\left(\sigma_{1}-\sigma_{3}\right)_{f}$ is determined according to the stress value corresponding to the strain value $\varepsilon_{1}=15 \%$; for the stress-strain curve with a peak value, it generally takes its strength, that is, $\left(\sigma_{1}-\sigma_{3}\right)_{f}=\left(\sigma_{1}-\sigma_{3}\right)_{\text {peak }}$

In this way, the damage ratio $R_{f}$ can be defined as

$$
R_{f}=\frac{\left(\sigma_{1}-\sigma_{3}\right)_{f}}{\left(\sigma_{1}-\sigma_{3}\right)_{\mathrm{ult}}} \text {. }
$$

Considering (5), one has

$$
\begin{aligned}
b & =\frac{1}{\left(\sigma_{1}-\sigma_{3}\right)_{\mathrm{ult}}}, \\
& =\frac{R_{f}}{\left(\sigma_{1}-\sigma_{3}\right)_{f}} .
\end{aligned}
$$

Consider $E_{t}$ as a function of stress, which can be obtained by transforming (2):

$$
\varepsilon_{1}=\frac{a\left(\sigma_{1}-\sigma_{3}\right)}{1-b\left(\sigma_{1}-\sigma_{3}\right)} .
$$

Substituting (8) into (3), we get

$$
E_{t}=\frac{1}{a\left[1 /\left(1-b\left(\sigma_{1}-\sigma_{3}\right)\right)\right]^{2}} \text {. }
$$

Substituting (4) and (7) into (9), we can get

$$
E_{t}=E_{i}\left[1-R_{f} \frac{\left(\sigma_{1}-\sigma_{3}\right)}{\left(\sigma_{1}-\sigma_{3}\right)_{f}}\right]^{2}
$$

According to the Mohr-Coulomb strength criterion, there is

$$
\left(\sigma_{1}-\sigma_{3}\right)_{f}=\frac{2 c \cos \varphi+2 \sigma_{3} \sin \varphi}{1-\sin \varphi} .
$$

The expression of the initial elastic modulus $E_{i}$ with consolidation pressure $\sigma_{3}$ can be described as

$$
E_{i}=K p_{a}\left(\frac{\sigma_{3}}{p_{a}}\right)^{n}
$$

where $p_{a}$ is the atmospheric pressure $\left(p_{a}=101.4 \mathrm{kPa}\right)$ and $K$ and $n$ are experimental parameters, representing the intercept and slope of the straight line between $\log \left(E_{i} / p_{a}\right)$ and $\log \left(\sigma_{3} / p_{\mathrm{a}}\right)$.

Substituting (11) and (12) into (10), we can obtain

$$
E_{t}=K p_{a}\left(\frac{\sigma_{3}}{p_{a}}\right)^{a}\left[1-R_{f} \frac{\left(\sigma_{1}-\sigma_{3}\right)(1-\sin \varphi)}{2 c \cos \varphi+2 \sigma_{3} \sin \varphi}\right]^{2} \text {. }
$$

In (13), the tangent elastic modulus $E_{t}$ contains five material parameters $\left(K, n, c, \varphi\right.$, and $\left.R_{f}\right)$. There is a hyperbolic relationship between the axial strain $\varepsilon_{1}$ and the confining strain $-\varepsilon_{3}$ based on the conventional triaxial loading test data of the soil (Figure 5).

The hyperbolic equation shown in Figure 5(a) can be written as

$$
\varepsilon_{1}=\frac{-\varepsilon_{3}}{f+D\left(-\varepsilon_{3}\right)} \text {. }
$$

The linear equation in Figure 5(b) can be written as

$$
\begin{aligned}
-\left(\frac{\varepsilon 3}{\varepsilon_{1}}\right) & =f+D(-\varepsilon 3) \\
& =f-D(\varepsilon 3) .
\end{aligned}
$$

When $\varepsilon_{3}=0,-\varepsilon_{3} / \varepsilon_{1}=f=v_{i}$ is initial Poisson's ratio; when $-\varepsilon_{3} \longrightarrow \infty, D=1 /\left(\varepsilon_{1}\right)_{\text {ult }}$. The triaxial shear test shows that 


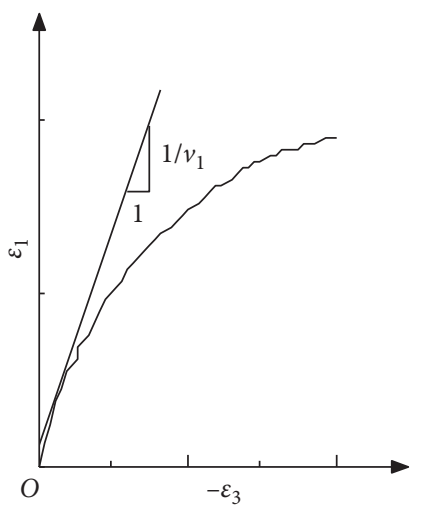

(a)

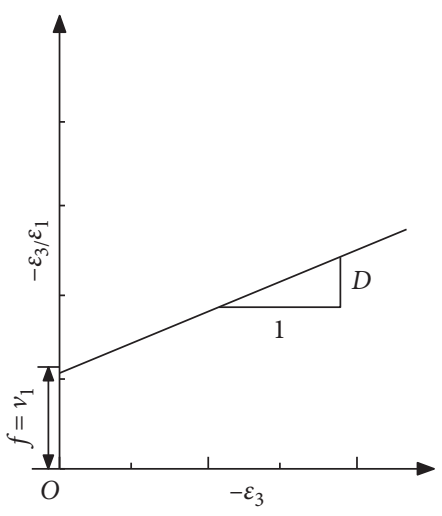

(b)

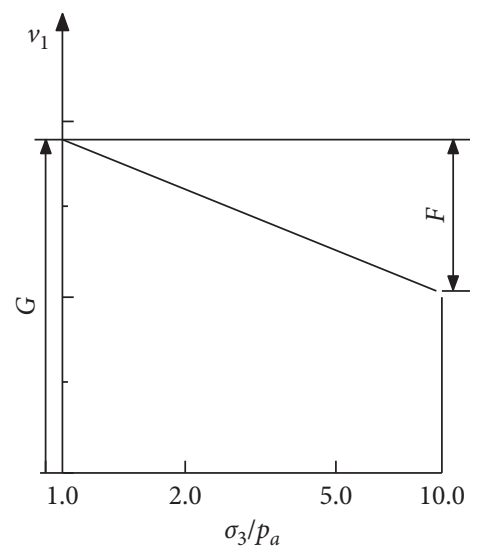

(c)

Figure 5: Determination of the relevant parameters of tangent Poisson's ratio: (a) $\varepsilon_{1}$ and $-\varepsilon_{3},(\mathrm{~b})-\varepsilon_{3} / \varepsilon_{1}$ and $-\varepsilon_{3}$, and (c) $v$ and log $\left(\sigma_{3} / \mathrm{Pa}\right)$.

initial Poisson's ratio is related to the confining pressure $[9,12]$. As shown in Figure 5(c), it is assumed that

$$
\begin{aligned}
v_{i} & =f, \\
& =G-F \lg \left(\frac{\sigma_{3}}{p_{a}}\right),
\end{aligned}
$$

where $G$ and $F$ are test constants.
The difference of (14) induces

$$
\begin{aligned}
v_{t} & =\frac{-\mathrm{d} \varepsilon_{3}}{\mathrm{~d} \varepsilon_{1}}, \\
& =\frac{v_{i}}{\left(1-D \varepsilon_{1}\right)^{2}} .
\end{aligned}
$$

Substituting (8) and (16) into (17), we get

$$
v_{t}=\frac{G-F \lg \left(\sigma_{3} / p_{a}\right)}{\left\{1-D\left(\sigma_{1}-\sigma_{3}\right) /\left(K p_{a}\left(\sigma_{3} / p_{a}\right)^{n}\left[1-R_{f}\left(\left(\sigma_{1}-\sigma_{3}\right)(1-\sin \varphi)\right) /\left(2 c \cos \varphi+2 \sigma_{3} \sin \varphi\right)\right]\right)\right\}^{2}} .
$$

4.2. Conventional Triaxial Unloading Test. Assuming that the soil is an isotropic medium, according to the generalized Hooke's law, the stress-strain relationship can be written as

$$
E_{t}=\frac{\Delta \sigma_{a}\left(\Delta \sigma_{a}+\Delta \sigma_{r}\right)-2 \Delta \sigma_{r}^{2}}{\Delta \varepsilon_{a}\left(\Delta \sigma_{a}+\Delta \sigma_{r}\right)-2 \Delta \varepsilon_{r} \sigma_{r}}
$$

where $\Delta \sigma_{a}=\Delta \sigma_{1}$ is the axial stress increment, $\Delta \sigma_{r}=\Delta \sigma_{3}$ is the lateral stress increment, $\Delta \varepsilon_{a}=\Delta \varepsilon_{1}$ is the axial strain increment, and $\Delta \varepsilon_{r}=\Delta \varepsilon_{3}$ is the lateral strain increment.

When $\Delta \sigma_{a}=0$ and $\Delta \sigma_{r} \neq 0$, the tangent elastic modulus $E_{t}$ can be written as

$$
\begin{aligned}
E_{t} & =\frac{12 \Delta \sigma_{r}}{\Delta \varepsilon_{a}-2 \Delta \varepsilon_{r}}, \\
& =\frac{\partial\left[2\left(\sigma_{a}-\sigma_{r}\right)\right]}{\partial\left(\varepsilon_{a}-2 \varepsilon_{r}\right)} .
\end{aligned}
$$

Referring to the derivation process of the triaxial loading test, under the condition of lateral unloading, the relationship curve of $2\left(\sigma_{r c}-\sigma_{r}\right)-\left(\varepsilon_{a}-2 \varepsilon_{r}\right)$ is still satisfied with a hyperbolic relationship, namely, $\left(\varepsilon_{a}-2 \varepsilon_{r}\right) /$ $2\left(\sigma_{r c}-\sigma_{r}\right)-\left(\varepsilon_{a}-\varepsilon_{r}\right)$.

Use (12) to establish the relationship between the initial tangent elastic modulus $E_{i}$ and the axial consolidation pressure $\sigma_{a c}$. Here, $E_{i}$ is actually the slope of the curve between $2\left(\sigma_{r c}-\sigma_{r}\right)$ and $\left(\varepsilon_{a}-2 \varepsilon_{r}\right)$ at the origin of the curve. Hence,

$$
E_{i}=K p_{a}\left(\frac{\sigma_{a c}}{p_{a}}\right)^{n} .
$$

During lateral unloading, the failure deviator stress can be deduced:

$$
\left(\sigma_{a}-\sigma_{r}\right)_{f}=\frac{2 c \cos \varphi+2 \sigma_{a c} \sin \varphi}{1+\sin \varphi} .
$$

Because $\sigma_{a}=\sigma_{a c}$ is a constant during lateral unloading, it can be obtained from (20): 


$$
E_{t}=K p_{a}\left(\frac{\sigma_{a c}}{p_{a}}\right)^{n}\left\{1-R_{f} \frac{\left(\sigma_{r c}-\sigma_{r}\right)(1+\sin \varphi)}{2 c \cos \varphi+2 \sigma_{a c} \sin \varphi-\left(\sigma_{a c}-\sigma_{r c}\right)(1+\sin \varphi)}\right\} .
$$

The tangential elastic modulus $E_{t}$ of the triaxial unloading test still contains 5 material constants (i.e., $K, n, c$, $\varphi$, and $R_{f}$ ). Comparing the unloading and loading paths, it can be seen that the axial strain $\varepsilon_{1}$ increases and $\varepsilon_{3}$ decreases. That is, the two effects on the test results are the same. From this point of view, the calculation formula of Poisson's ratio for loading and unloading tests is the same. Therefore, the final expression of tangent Poisson's ratio in the unloading test is

$$
v_{t}=\frac{G-F \lg \left(\sigma_{3} / p_{a}\right)}{\left\{1-D\left(\sigma_{1}-\sigma_{3}\right) /\left(K p_{a}\left(\sigma_{3} / p_{a}\right)^{n}\left[1-r_{f}\left(\left(\sigma_{1}-\sigma_{3}\right)(1-\sin \varphi)\right) /\left(2 c \cos \varphi+2 \sigma_{3} \sin \varphi\right)\right]\right)\right\}^{2}} .
$$

\section{Determination of Loading/ Unloading Parameters}

5.1. Parameters of the Triaxial Loading. According to the stress-strain relationship shown in Figure 2, three groups of confining pressures and corresponding failure stresses $\left(\sigma_{1}-\sigma_{3}\right)_{f}$ are obtained, as shown in Table 3. Thus, we can obtain the cohesive force $c=19.2 \mathrm{kPa}$ and the friction angle $\varphi=40^{\circ}$. In the coordinates of $\varepsilon_{1}$ and $\varepsilon_{1} /\left(\sigma_{1}-\sigma_{3}\right)$, the relationship between the two is approximately linear (Figure 6). In Figure 6, $a$ and $b$ are the intercept and slope obtained by fitting a straight line. Combining equation (24), the $E_{i}$ value can be obtained as shown in Table 4 .

Figure 6 indicates that $\varepsilon_{1}$ and $\varepsilon_{1} /\left(\sigma_{1}-\sigma_{3}\right)$ of sandy gravel have a good linear relationship, which means a hyperbolic relationship between shear stress and strain. The determination parameter $R^{2}$ values are all greater than 0.98 , and the hyperbolic model has better applicability. Combining (7) can calculate the values of $R_{f}$ to be $0.91,0.93$, and 0.92 , and the average value is 0.92 .

According to (12), the following expression can be obtained:

$$
\lg \left(\frac{E_{i}}{p_{a}}\right)=\lg k+n \lg \left(\frac{\sigma_{3}}{p_{a}}\right)
$$

From the results in Table 4, three sets of $E_{i}$ and $\sigma_{3}$ values can be obtained. According to the fitting results, we can obtain the intercept $K=97$ and the slope $n=0.538$. According to the relationship between the axial strain of sandy gravel and the volume tric strain, the relationship of $-\varepsilon_{3} / \varepsilon_{1}$ and $-\varepsilon_{3}$ can be obtained as shown in Figure 7 . Figure 7 indicates that there is a good linear relationship between $-\varepsilon_{3}$ / $\varepsilon_{1}$ and $-\varepsilon_{3}$. By fitting the result to a straight line, the average value of the slope $D$ is 0.07 .

According to the three groups of values of $v_{i}$ and $\sigma_{3}$ in Figure 7, the relationship between $v_{i}$ and $\log \left(\sigma_{3} / p_{a}\right)$ is shown in Figure 8. Due to $v_{i}=G-F \lg \left(\sigma_{3} / p_{a}\right)$, the parameters $G=0.49$ and $F=0.186$ can be obtained.

5.2. Parameters for Triaxial Unloading. A large number of experimental studies [13-15] show that the cohesion $c$ and the friction angle $\varphi$ in the unloading test are equal to those in the load test, that is, the cohesion $c$ is $19.2 \mathrm{kPa}$ and the friction angle $\varphi$ is $40^{\circ}$. The damage ratio $R_{f}$ of the unloading test is consistent with (26). In the coordinates $\left(\varepsilon_{1}-2 \varepsilon_{3}\right)$ / $2\left(\sigma_{1}-\sigma_{3}\right)-\left(\varepsilon_{1}-2 \varepsilon_{3}\right)$ (Figure 9$)$, the linear fitting results are poor. This is because high or low stress levels will cause the test point to deviate from the straight line.

The relevant values obtained according to this method are shown in Table 5, and the fitted straight line relationship is shown in Figure 10. Combining the stress paths of the unloading test, there are

$$
\begin{array}{r}
E_{i}=\frac{1}{a}, \\
2\left(\sigma_{1}-\sigma_{3}\right)_{\mathrm{ult}}=\frac{1}{b},
\end{array}
$$

where $a$ and $b$ are the intercepts and slopes obtained by fitting in Figure 4.

Combining the results in Figure 4, the relevant parameters of the unloading test and $E_{\mathrm{i}}$ and $R_{f}$ can be obtained (Table 6). Finally, the average value of $R_{f}$ in the sandy gravel unloading test can be obtained from Table 6, namely, $R_{f}=0.43$. Using (21), the following equation can be obtained:

$$
\lg \left(\frac{E_{i}}{p_{a}}\right)=\lg K+\lg \left(\frac{\sigma_{1}}{p_{a}}\right)
$$

where $K$ represents the intercept and $n$ represents the slope.

According to Table 6, three groups of $E_{i}$ and $\sigma_{1}$ values can be obtained to fit a straight line, and the expression is

$$
\lg \left(\frac{E_{i}}{p_{a}}\right)=1 \cdot 6322+0 \cdot 759 \lg \left(\frac{\sigma_{1}}{p_{a}}\right) .
$$

Comparing (28) and (29), we can obtain that intercept $K=43$ and slope $n=0.759$. Finally, the parameters $G, F$, and $D$ related to tangent Poisson's ratio are determined. Figure 5 shows the relationship between the axial strain and the body strain and the relationship between $-\varepsilon_{3} / \varepsilon_{1}$ and $-\varepsilon_{3}$ (Figure 11). 
TABLE 3: Failure stress under loading conditions.

\begin{tabular}{lcc}
\hline$\sigma_{3}(\mathrm{kPa})$ & $\left(\sigma_{1}-\sigma_{3}\right)_{f}(\mathrm{kPa})$ & $\left(\sigma_{1}\right)_{f}(\mathrm{kPa})$ \\
\hline 200 & 800 & 1000 \\
400 & 1529 & 1929 \\
600 & 2238 & 2838 \\
\hline
\end{tabular}

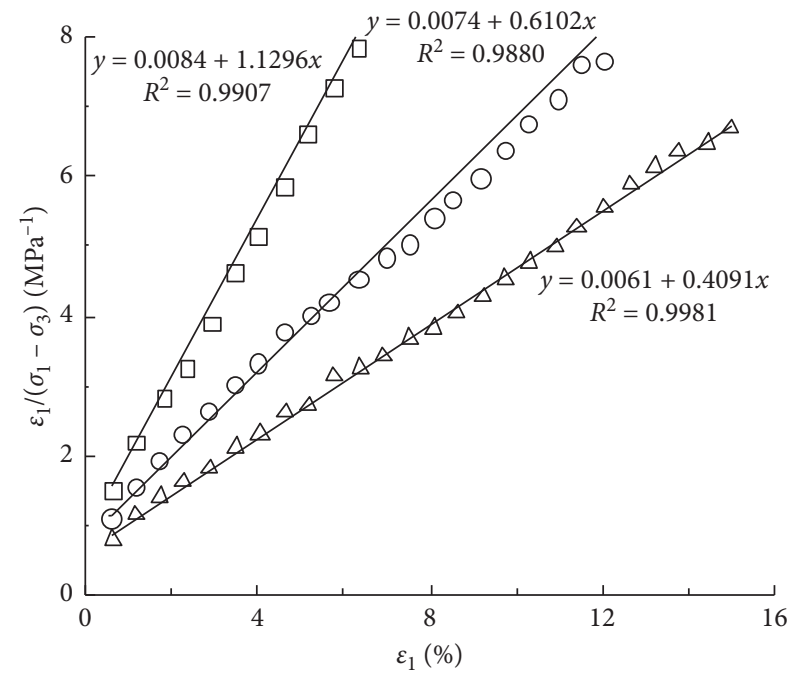
$\square \sigma_{1}=0.2 \mathrm{MPa}$
— Fitting line, $0.2 \mathrm{MPa}$
○ $\sigma_{1}=0.4 \mathrm{MPa}$
— Fitting line, $0.4 \mathrm{MPa}$
$\triangle \sigma_{1}=0.6 \mathrm{MPa}$
—_ Fitting line, 0.6 MPa

FIgURE 6: Relationship between $\varepsilon_{1}$ and $\varepsilon_{1} /\left(\sigma_{1}-\sigma_{3}\right)$.

TABle 4: Model parameters of the triaxial loading test (unit: MPa).

\begin{tabular}{cccc}
\hline$\sigma_{3}$ & $a$ & $b$ & $E_{i}$ \\
\hline 0.2 & 0.0084 & 1.1296 & 119.05 \\
0.4 & 0.0074 & 0.6102 & 135.14 \\
0.6 & 0.0061 & 0.4091 & 163.93 \\
\hline
\end{tabular}

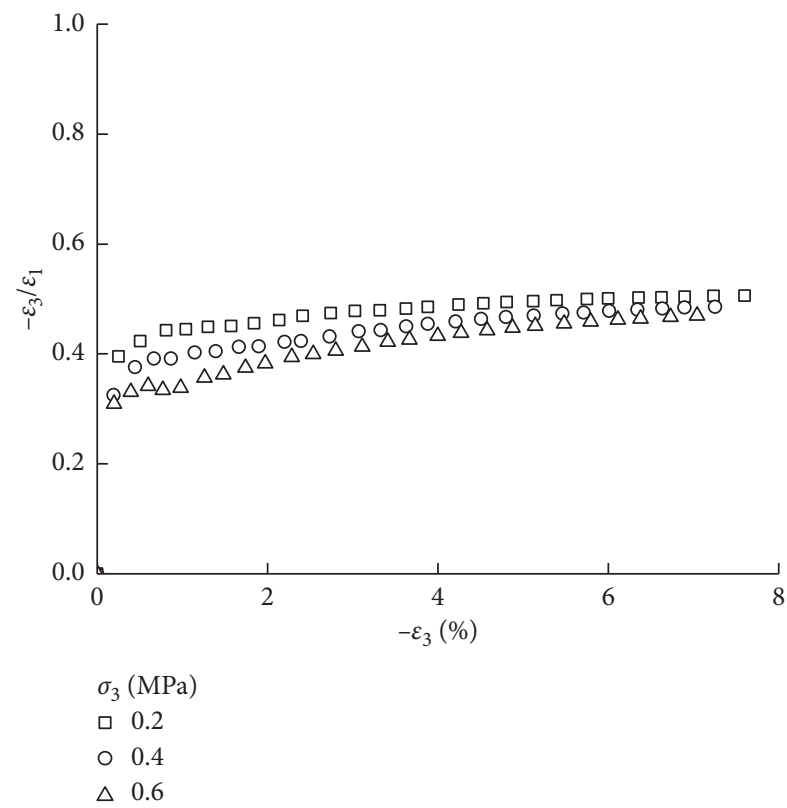

FIgURE 7: Relationship between $-\varepsilon_{3} / \varepsilon_{1}$ and $-\varepsilon_{3}$.

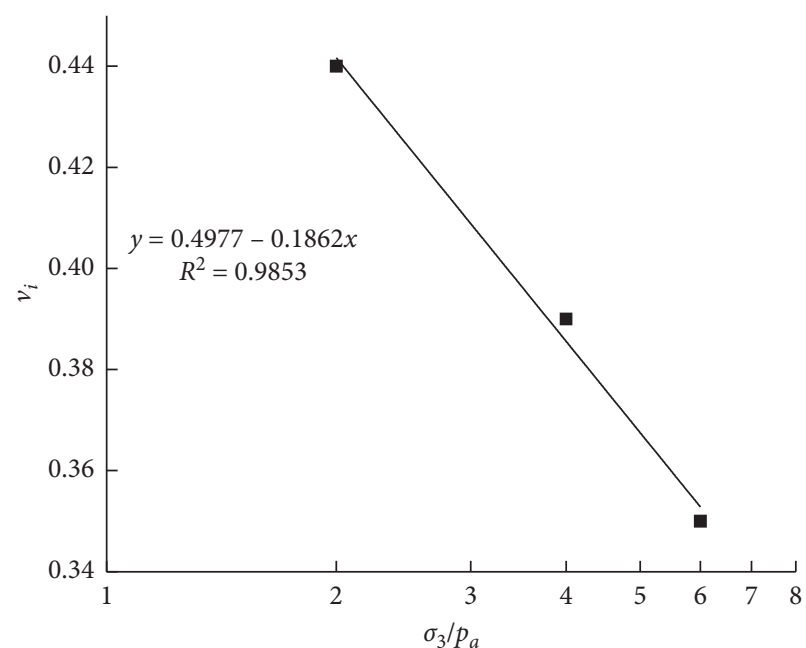

Figure 8: Relationship between $v_{i}$ and $\log \left(\sigma_{3} / \mathrm{Pa}\right)$.

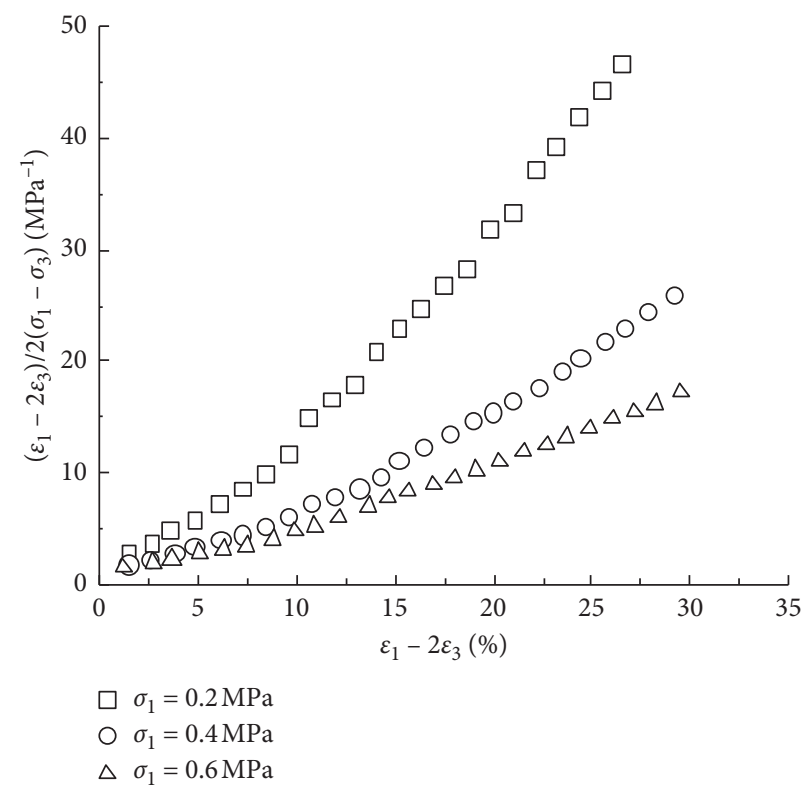

FIGURE 9: Relationship between $\left(\varepsilon_{1}-2 \varepsilon_{3}\right) / 2\left(\sigma_{1}-\sigma_{3}\right)$ and $\left(\varepsilon_{1}-2 \varepsilon_{3}\right)$.

TABLE 5: Failure stress under unloading conditions.

\begin{tabular}{lcccccc}
\hline & \multicolumn{2}{c}{$\varepsilon_{1}-\varepsilon_{3}$} & \multicolumn{2}{c}{$\varepsilon_{1}-2 \varepsilon_{3}$} & \multicolumn{2}{c}{$\left(\varepsilon_{1}-2 \varepsilon_{3}\right) /$} \\
$\varepsilon_{1}$ & \multicolumn{2}{c}{$2\left(\varepsilon_{1}-\varepsilon_{3}\right)$} \\
& $70 \%$ & $90 \%$ & $70 \%$ & $90 \%$ & $70 \%$ & $90 \%$ \\
\hline 0.2 & 0.29 & 0.37 & 1.9 & 3.8 & 3.3 & 5.2 \\
0.4 & 0.55 & 0.7 & 2.48 & 5.2 & 2.2 & 3.7 \\
0.6 & 0.75 & 0.97 & 3.4 & 6.2 & 2.0 & 3.14 \\
\hline
\end{tabular}

Figure 11 indicates that there is an obvious linear relationship between $-\varepsilon_{3} / \varepsilon_{1}$ and $-\varepsilon_{3}$, indicating that the assumption that the axial strain $\varepsilon_{1}$ and the lateral strain $\varepsilon_{3}$ are hyperbolic in the unloading test is applicable. The average value of the slope $D$ of the fitted straight line is -0.015 . According to Figure 11, three groups of values of $v_{i}$ and $\sigma_{3}$ 


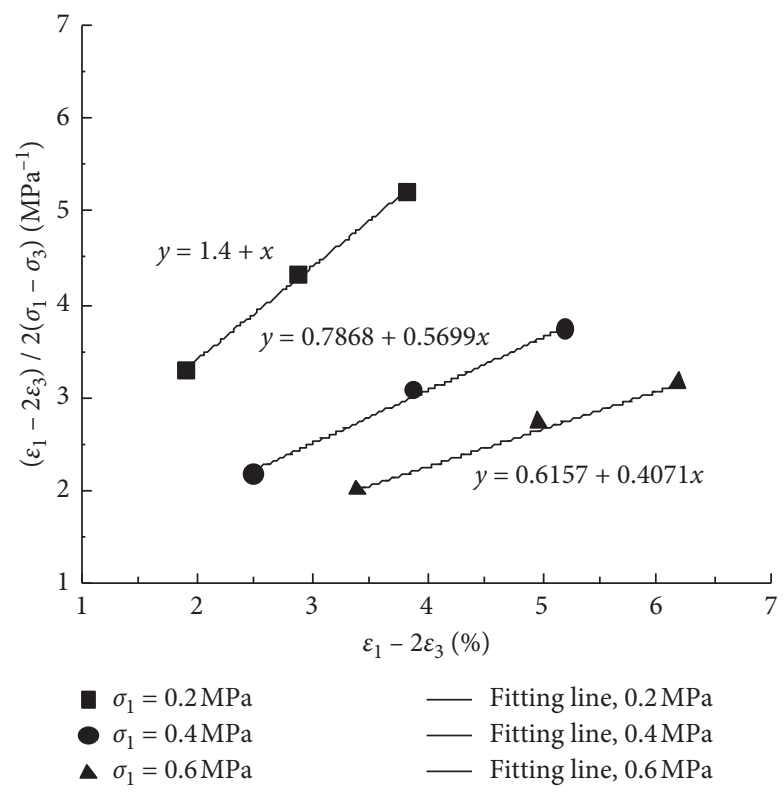

FIGURE 10: Relationship between $\left(\varepsilon_{1}-2 \varepsilon_{3}\right) / 2\left(\sigma_{1}-\sigma_{3}\right)$ and $\left(\varepsilon_{1}-2 \varepsilon_{3}\right)$.

TABle 6: Model parameters of the triaxial unloading test (unit: MPa).

\begin{tabular}{lcccc}
\hline$\sigma_{1}$ & $a$ & $b$ & $E_{i}$ & $R_{f}$ \\
\hline 0.2 & 0.014 & 1 & 71.43 & 0.42 \\
0.4 & 0.0078 & 0.56 & 128.21 & 0.43 \\
0.6 & 0.0062 & 0.41 & 162.60 & 0.43 \\
\hline
\end{tabular}

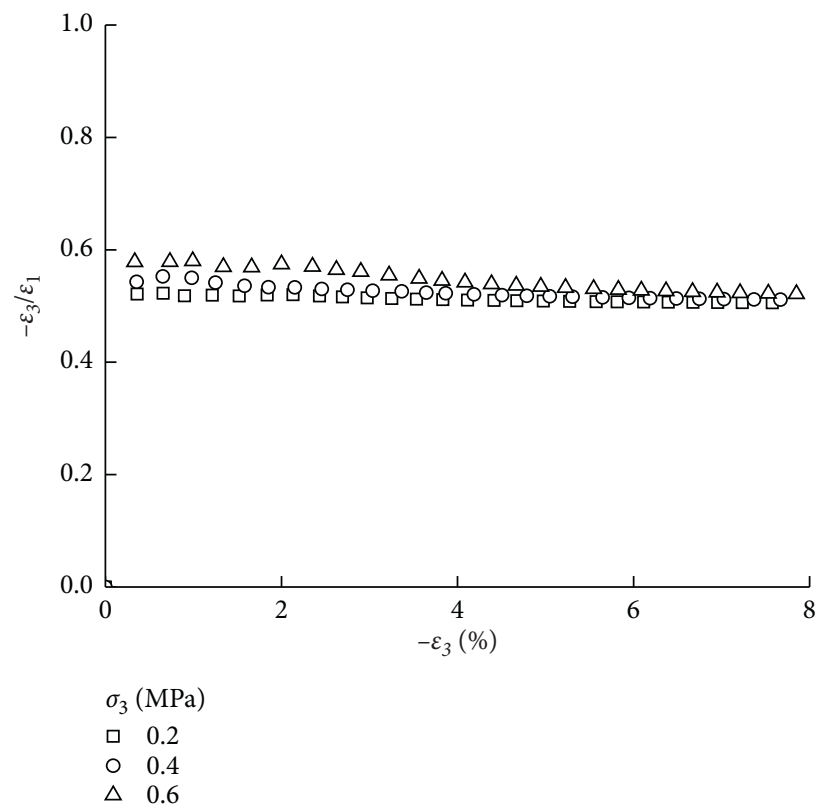

FIGURE 11: Relationship between $-\varepsilon_{3} / \varepsilon_{1}$ and $-\varepsilon_{3}$. 


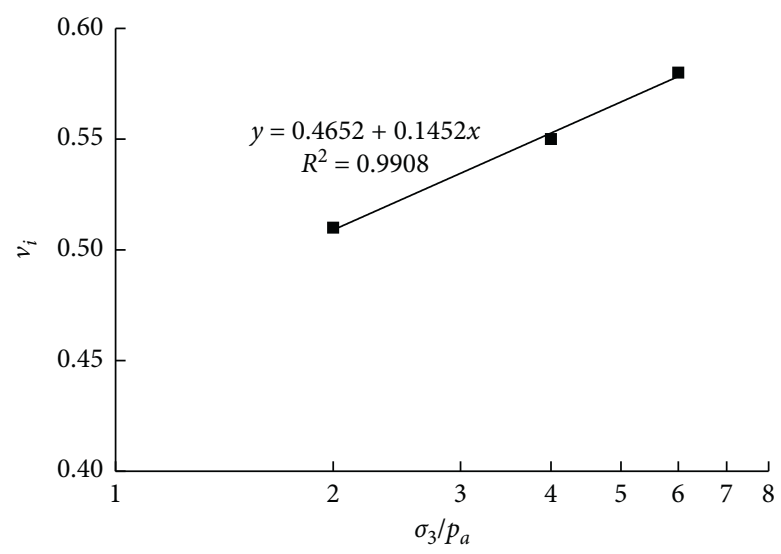

FIGURE 12: Relationship between $v_{i}$ and $\log \left(\sigma_{3} / p_{a}\right)$.

can be obtained, and the corresponding relationship between $v_{i}$ and $\log \left(\sigma_{3} / p_{\mathrm{a}}\right)$ can be drawn, as shown in Figure 12.

Due to

$$
v_{i}=G-F \lg \left(\frac{\sigma_{3}}{p_{a}}\right),
$$

the equation of the fitted straight line in Figure 12 is

$$
v_{i}=0 \cdot 47+0 \cdot 145 \lg \left(\frac{\sigma_{3}}{p_{a}}\right) \text {. }
$$

Comparing (30) and (31), the value of $G$ is 0.47 , and the value of $F$ is -0.145 .

5.3. The Tangent Elastic Modulus and Tangent Poisson's Ratio. For triaxial loading, according to the relevant parameters determined above, the tangent elastic modulus $E_{t}$ and tangent Poisson's ratio $v_{t}$ of sandy gravel under triaxial loading can be obtained as

$$
\begin{aligned}
& E_{t}=97 p_{a}\left(\frac{\sigma_{3}}{p_{a}}\right)^{0.538}\left[1-0 \cdot 92 \frac{\left(\sigma_{1}-\sigma_{3}\right)(1-\sin \varphi)}{38 \cdot 4 \cos 40^{0}+2 \sigma_{3} \sin 40^{0}}\right], \\
& v_{t}=\frac{0 \cdot 49-0 \cdot 186 \lg \left(\sigma_{3} / p_{a}\right)}{\left\{1-\left(0 \cdot 07\left(\sigma_{1}-\sigma_{3}\right) / 97 p_{a}\left(\sigma_{3} / p_{a}\right)^{0.538}\left[1-0 \cdot 92\left(\left(\sigma_{1}-\sigma_{3}\right)(1-\sin \varphi)\right) /\left(38 \cdot 4 \cos 40^{0}+2 \sigma_{3} \sin 40^{0}\right)\right]\right)\right\}^{2}} .
\end{aligned}
$$

For triaxial unloading, $E_{t}$ and $v_{t}$ during the unloading test are

$$
\begin{aligned}
& E_{t}=43 p_{a}\left(\frac{\sigma_{3}}{p_{a}}\right)^{0.759}\left[1-0 \cdot 43 \frac{\left(\sigma_{1}-\sigma_{3}\right)(1-\sin \varphi)}{38 \cdot 4 \cos 40^{0}+2 \sigma_{3} \sin 40^{0}}\right]^{2}, \\
& v_{t}=\frac{0 \cdot 47+0 \cdot 145 \lg \left(\sigma_{3} / p_{a}\right)}{\left\{\left(-0 \cdot 015\left(\sigma_{1}-\sigma_{3}\right)\right) / 43 p_{a}\left(\sigma_{3} / p_{a}\right)^{0.759}\left[1-0 \cdot 43\left(\left(\sigma_{1}-\sigma_{3}\right)(1-\sin \varphi)\right) /\left(38 \cdot 4 \cos 40^{0}+2 \sigma_{3} \sin 40^{0}\right)\right]\right\}^{2}} .
\end{aligned}
$$

\section{Conclusions}

Consolidation and drainage shear tests of sandy gravel under different confining pressures under loading/unloading conditions are carried out. The differences in the strength and deformation of sandy gravel are analyzed. In using the proposed model, the parameters are few and can be obtained from normal geotechnical tests, which has high application value in practical engineering. The main conclusions drawn are as follows:

(1) The relationships between $\sigma_{1}-\sigma_{3}$ and $\varepsilon_{1}$ and $\varepsilon_{v}$ and $\varepsilon_{a}$ of sandy gravel soil under loading conditions are all nonlinear. The smaller the confining pressure, the 
weaker the stress-strain relationship. The stressstrain relationship exhibits a softening phenomenon, and the bulk strain undergoes dilatancy deformation. In contrast, it shows strain hardening and shear shrinkage deformation.

(2) Under unloading conditions, the sandy gravel soil softens significantly with increasing confining pressure, and the peak strength increases. In the meantime, the tric strain response exhibits dilatancy characteristics. The strength and deformation characteristics of sandy gravel soil have a high dependence on the stress path.

(3) The Duncan-Chang hyperbolic model has good applicability for simulating sandy gravel soils, and the model parameters are calculated according to the test results, which can provide help for engineering design and practice.

\section{Abbreviations}

$\begin{array}{ll}\varepsilon_{1}, \varepsilon_{3}: & \text { Principal strains } \\ \varepsilon_{r}: & \text { Lateral strain } \\ \varepsilon_{v}: & \text { Bulk strain } \\ \sigma_{1}, \sigma_{3}: & \text { Principal stresses } \\ \sigma_{r c}: & \text { Lateral consolidation pressure } \\ \sigma_{r}: & \text { Lateral pressure } \\ E_{t}: & \text { Tangent elastic modulus } \\ E_{i}: & \text { Initial modulus of elasticity } \\ c: & \text { Cohesion } \\ \varphi: & \text { Internal friction angle } \\ p_{a}: & \text { Atmospheric pressure } \\ K, n, G, F: & \text { Material test constants } \\ v_{i}: & \text { Initial Poisson's ratio. }\end{array}$

\section{Data Availability}

The data used to support the findings of this study are available from the corresponding author upon request.

\section{Conflicts of Interest}

The authors declare that they have no conflicts of interest.

\section{Acknowledgments}

This research was supported by the Hebei Province Postdoctoral Research Project Merit-Based Funding Program (B2020005008).

\section{References}

[1] X. Li, T. Li, and L. Peng, "Elastoplastic two-surface model for unsaturated cohesive soils under cyclic loading," International Journal of Geomechanics, vol. 20, no. 8, Article ID 04020122, 2020.

[2] L. Zhu, G. Wang, F. Huang, Y. Li, W. Chen, and H. Hong, "Landslide susceptibility prediction using sparse feature extraction and machine learning models based on GIS and remote sensing," IEEE Geoscience and Remote Sensing Letters, vol. 15, pp. 1-5, 2021.
[3] B. Bai, S. Jiang, L. Liu, X. Li, and H. Wu, "The transport of silica powders and lead ions under unsteady flow and variable injection concentrations," Powder Technology, vol. 387, pp. 22-30, 2021.

[4] M. Aslani, J. Nazariafshar, and N. Ganjian, "Experimental study on shear strength of cohesive soils reinforced with stone columns," Geotechnical and Geological Engineering, vol. 37, no. 3, pp. 2165-2188, 2019.

[5] A. M. Deganutti, P. R. Tecca, and R. Genevois, "The measure of friction angles for different types of granular material," Journal of Mountain Science, vol. 16, no. 4, pp. 769-777, 2019.

[6] B. Bai, D. Rao, T. Chang, and Z. Guo, "A nonlinear attachment-detachment model with adsorption hysteresis for suspension-colloidal transport in porous media," Journal of Hydrology, vol. 578, Article ID 124080, 2019.

[7] B. Bai, T. Xu, Q. Nie, and P. Li, “Temperature-driven migration of heavy metal $\mathrm{Pb} 2+$ along with moisture movement in unsaturated soils," International Journal of Heat and Mass Transfer, vol. 153, Article ID 119573, 2020.

[8] M. Sánchez, A. Gens, M. V. Villar, and S. Olivella, "Fully coupled thermo-hydro-mechanical double-porosity formulation for unsaturated soils," International Journal of Geomechanics, vol. 16, no. 6, pp. 1-38, 2016.

[9] E. Gholizadeh and M. Latifi, "A coupled hydro-mechanical constitutive model for unsaturated frictional and cohesive soil," Computers and Geotechnics, vol. 98, pp. 69-81, 2018.

[10] B. Bai, D. Rao, T. Xu, and P. Chen, "SPH-FDM boundary for the analysis of thermal process in homogeneous media with a discontinuous interface," International Journal of Heat and Mass Transfer, vol. 117, pp. 517-526, 2018.

[11] G. Yang and B. Bai, "Thermo-hydro-mechanical model for unsaturated clay soils based on granular solid hydrodynamics theory," International Journal of Geomechanics, vol. 19, no. 10, Article ID 04019115, 2019.

[12] F. Huang, Z. Ye, S.-H. Jiang, J. Huang, Z. Chang, and J. Chen, "Uncertainty study of landslide susceptibility prediction considering the different attribute interval numbers of environmental factors and different data-based models," Catena, vol. 202, Article ID 105250, 2021.

[13] F. Huang, Z. Cao, S.-H. Jiang, C. Zhou, J. Huang, and Z. Guo, "Landslide susceptibility prediction based on a semi-supervised multiple-layer perceptron model," Landslides, vol. 17, no. 12, pp. 2919-2930, 2020.

[14] E. E. Alonso, A. Gens, and A. Josa, "A constitutive model for partially saturated soils," Géotechnique, vol. 40, no. 3, pp. 405-430, 1990.

[15] B. Bai, L. Guo, and S. Han, "Pore pressure and consolidation of saturated silty clay induced by progressively heating/ cooling," Mechanics of Materials, vol. 75, pp. 84-94, 2014.

[16] S. L. Houston, "It is time to use unsaturated soil mechanics in routine geotechnical engineering practice," Journal of Geotechnical and Geoenvironmental Engineering, vol. 145, no. 5, Article ID 02519001, 2019.

[17] B. Bai and Z. Su, "Thermal responses of saturated silty clay during repeated heating-cooling processes," Transport in Porous Media, vol. 93, no. 1, pp. 1-11, 2012.

[18] B. Bai and X. Shi, "Experimental study on the consolidation of saturated silty clay subjected to cyclic thermal loading," Geomechanics and Engineering, vol. 12, no. 4, pp. 707-721, 2017.

[19] K. S. Wong and D. Mašín, "Coupled hydro-mechanical model for partially saturated soils predicting small strain stiffness," Computers and Geotechnics, vol. 61, pp. 355-369, 2014. 
[20] B. Bai, F. Long, D. Rao, and T. Xu, "The effect of temperature on the seepage transport of suspended particles in a porous medium," Hydrological Processes, vol. 31, no. 2, pp. 382-393, 2017.

[21] H. Ghasemzadeh and S. A. Ghoreishian Amiri, "A hydromechanical elastoplastic model for unsaturated soils under isotropic loading conditions," Computers and Geotechnics, vol. 51, pp. 91-100, 2013.

[22] B. Bai, G.-C. Yang, T. Li, and G.-S. Yang, "A thermodynamic constitutive model with temperature effect based on particle rearrangement for geomaterials," Mechanics of Materials, vol. 139, Article ID 103180, 2019.

[23] A. Hamrouni, D. Dias, and B. Sbartai, "Probability analysis of shallow circular tunnels in homogeneous soil using the surface response methodology optimized by a genetic algorithm," Tunnelling and Underground Space Technology, vol. 86, pp. 22-33, 2019.

[24] Z. Zizka, B. Schoesser, M. Thewes, and T. Schanz, "Slurry shield tunneling: new methodology for simplified prediction of increased pore pressures resulting from slurry infiltration at the tunnel face under cyclic excavation processes," International Journal of Civil Engineering, vol. 17, no. 1, pp. 113-130, 2019.

[25] L. Flessati and C. Di Prisco, "Deep tunnel faces in cohesive soils under undrained conditions: application of a new design approach," European Journal of Environmental and Civil Engineering, vol. 32, Article ID 1785332, 2018.

[26] H. R. Huang, J. G. Zhu, and Z. R. Fang, "Triaxial test study of deformation and strength behavior of sand-gravel materials," Water Resources and Power, vol. 30, no. 7, pp. 87-89, 2012.

[27] M. C. Liu, X. M. Huang, and Y. F. Gao, "Research on strengthdeformation characteristics and nonlinear elastic model of rockfills," Rock and Soil Mechanics, vol. 25, no. 5, pp. 798-802, 2004.

[28] G. Zhang and J. M. Zhang, "Study on behavior of coarsegrained soil and its modeling," Rock and Soil Mechanics, vol. 25, no. 10, pp. 1587-1591, 2004.

[29] B. Indraratna, D. Ionescu, and H. D. Christie, "Shear behavior of railway ballast based on large-scale triaxial tests," Journal of Geotechnical and Geoenvironmental Engineering, vol. 124, no. 5, pp. 439-449, 1998.

[30] P. Zhang, B. Bai, S. Jiang, P. Wang, and H. Li, “Transport and deposition of suspended particles in saturated porous media: effect of hydrodynamic forces and pore structure," Water Science and Technology: Water Supply, vol. 16, no. 4, pp. 951-960, 2016.

[31] B. Bai, Q. Nie, Y. Zhang, X. Wang, and W. Hu, "Cotransport of heavy metals and $\mathrm{SiO} 2$ particles at different temperatures by seepage," Journal of Hydrology, vol. 597, Article ID 125771, 2021.

[32] D. Rao and B. Bai, "Study of the factors influencing diffusive tortuosity based on pore-scale SPH simulation of granular soil," Transport in Porous Media, vol. 132, no. 2, pp. 333-353, 2020.

[33] W. Li, X. Fan, F. Huang et al., "Uncertainties analysis of collapse susceptibility prediction based on remote sensing and GIS: influences of different data-based models and connections between collapses and environmental factors," Remote Sensing, vol. 12, no. 24, p. 4134, 2020.

[34] B. Mi and Y. Xiang, "Analysis of the limit support pressure of a shallow shield tunnel in sandy soil considering the influence of Seepage," Symmetry, vol. 12, no. 6, p. 1023, 2020.

[35] S. Zingg and G. Anagnostou, "Tunnel face stability and the effectiveness of advance drainage measures in water-bearing ground of non-uniform permeability," Rock Mechanics and Rock Engineering, vol. 51, no. 1, 2017.

[36] B. Bai, "Thermal response of saturated porous spherical body containing a cavity under several boundary conditions," Journal of thermal Stresses, vol. 36, no. 11, pp. 1217-1232, 2013.

[37] B. Bai and T. Li, "Irreversible consolidation problem of a saturated porothermoelastic spherical body with a spherical cavity," Applied Mathematical Modelling, vol. 37, no. 4, pp. 1973-1982, 2013.

[38] T. Qiu, C. Liu, X. Zhong, and Y. Zhu, "Experimental research on the impact of temperature on the adhesion characteristics of soil-structure interface," Geofluids, vol. 2020, Article ID 6675576, 9 pages, 2020.

[39] Z.-G. Yan, Y. Zhang, Y. Shen, H.-H. Zhu, and Y. Lu, "A multilayer thermo-elastic damage model for the bending deflection of the tunnel lining segment exposed to high temperatures," Tunnelling and Underground Space Technology, vol. 95, Article ID 103142, 2020.

[40] R. L. Kondner, "Hyperbolic stress-strain response: cohesive soils," Journal of Soil Mechanics and Foundation Engineering, vol. 89, no. 1, pp. 115-143, 1963.

[41] J. M. Duncan and C.-Y. Chang, "Nonlinear analysis of stress and strain in soils," Journal of Soil Mechanics and Foundation Engineering, vol. 96, no. 5, pp. 1629-1653, 1970.

[42] B. O. Hardin and V. P. Drnevich, "Shear modulus and damping in soils: design equations and curves," Journal of the Soil Mechanics and Foundation Division, vol. 98, no. 7, pp. 667-692, 1972. 